\title{
Adjustable Casts
}

EMMANOUIL VERMISSO

Florida Atlantic University

JUANITA BERNAL

Florida Atlantic University

The design proposals Jørn Utzon completed for the structural resolution of the Sydney Opera House (1956-57/completed 1973), Kuwait National Assembly (1971-71/ completed 1985)and Zurich Theatre (1964, unbuilt), examine the relationship between shape (structural profile) and material performance. Virtually, the roof modules of these projects consist of infinite numbers of structurally efficient profiles which are expressed through a geometric continuity. Using profile succession from ' $T$ ' to " $U$ ", among other combinations, Utzon explored the location of "material where it is structurally most useful" (M A Andersen 2014). These studies examine the analogue algorithm used by Ove Arup and Jørn Utzon to design the concourse beams (often called the "moment" beams) at the Sydney Opera House. The beam design is based on optimal material arrangement, in an attempt to unite form and structure: towards mid-span, where bending moment is greater, the beam cross-section assumes the shape of $a$ " $T$ " while the cross-section at the end conditions turns into a "U". The surface geometry of the beam is defined by interpolating between these three conditions ( $U$ to $T$ to $U$ ), resulting in a fluid, doubly curved geometry that ranges between these two shapes, thereby creating a 'family' of shapes.

In spite of Arup and Utzon's disagreement on the success of this particular design, this analogue algorithm enabled the reconciling of aesthetic language with structural performance,

\section{MARCO MANDRA}

Florida Atlantic University

\section{SITKI SIPAHI}

Florida Atlantic University

in a process that is geared towards bottom-up thinking. We are interested in the design thinking for the beams, during a time (early to mid-1960s) when advanced modeling software was not available. This study has recreated the algorithm for the Sydney beam using a parametric definition in Grasshopper ${ }^{\circledR}$, then adjusted the algorithm settings to create variations. We are interested to assess aesthetic outcomes relative to structural efficiency and shadow patterns on the double curvature of the beams.

The original beam and one variation have been fabricated and presented here; future development includes consideration for an adjustable cast which allows easy fabrication of several variations of the Sydney beam. A prototype was made that allows translation from $\mathrm{U}$ to a $\mathrm{T}$ using a Lego ${ }^{\circledR}$ motor and 3d-printed parts (shown below).

\section{REFERENCES}

Andersen, M A, 2013: Chapter 4: Construction, in Jørn Utzon: Drawings and Buildings, Princeton Architectural Press, NY 


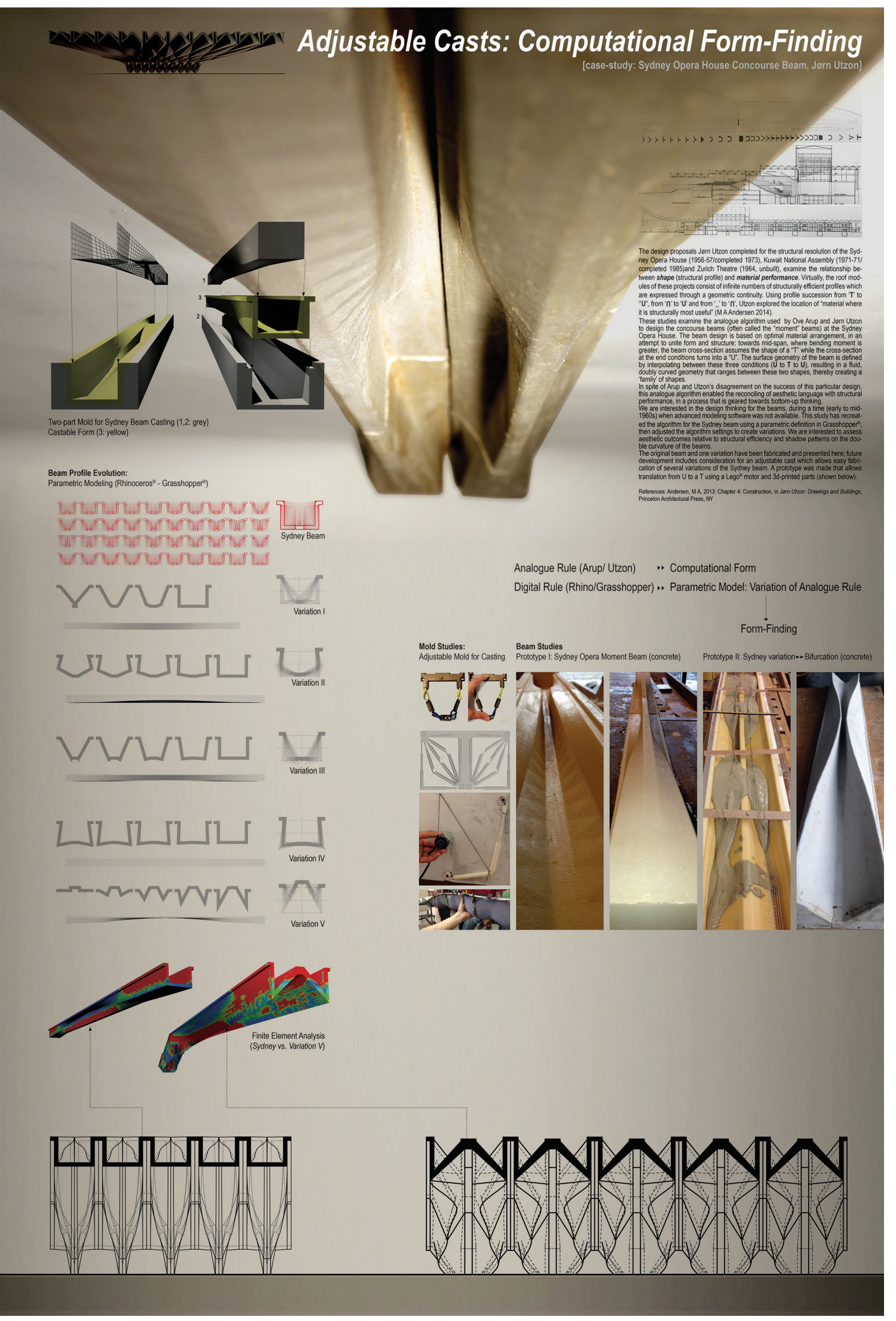

